\title{
Contractility of papillary muscle from rats exposed to 28 days of hypoxia, hypercapnia, and hypoxia with hypercapnia
}

\author{
SIMON V BAUDOUIN, NIGEL T BATEMAN \\ From the Department of Medicine, United Medical and Dental Schools, St Thomas's Campus, London
}

ABSTRACT The effects of chronic respiratory failure (hypoxia and hypercapnia) on the contractileio properties of cardiac muscle are not established. A study was performed of the isometric contractileo properties of isolated papillary muscle removed from rats exposed in a normobaric environmentaB chamber to 28 days of hypoxia (fractional inspired oxygen $\left(\mathrm{FIO}_{2}\right) 10 \%$, fractional inspired carbon dioxide $\left.\left(\mathrm{FICO}_{2}\right)<1 \%\right)$, hypercapnia $\left(\mathrm{FIO}_{2} 21 \%\right.$, FiCO $\left.2 \%\right)$, and hypoxia with hypercapnia $\left(\mathrm{FIO}_{2} 10 \%\right.$ $\mathrm{FICO}_{2} 5 \%$ ). Rats exposed to both hypoxia and hypoxia with hypercapnia developed selective righe ventricular hypertrophy. Exposure to hypercapnia alone did not alter right ventricular weight. No는 change in right ventricular papillary muscle contractility per unit muscle mass was observed as, measured by maximum active tension, maximum rate of rise or fall of tension, or time to peak tension. Rat cardiac muscle adapts successfully to the altered acid-base environment and increased work load associated with prolonged exposure to hypoxia and mild hypercapnia.

\section{Introduction}

The functional state of the right ventricle in patients with chronic bronchitis and emphysema is controversial, with evidence for both normal and reduced contractility. ${ }^{1-5}$ Information about the contractile performance of the right ventricle is important in view of the suggestion that pulmonary vasodilators may benefit patients with chronic respiratory failure ${ }^{6}$ by lowering pulmonary artery pressure when contractile function is compromised. Experimentally cardiac muscle dysfunction often occurs before the onset of pump failure, ${ }^{7}$ but the direct study of cardiac muscle function in patients with chronic bronchitis is impossible. The cardiopulmonary circulation of the rat is similar to that of $\operatorname{man}^{89}$ and its response to hypoxia resembles that in man. We have used the laboratory rat to study the effects of exposure to prolonged hypoxia, hypercapnia, and hypoxia with hypercapnia on cardiac muscle function.

Address for reprint requests: Dr N T Bateman, St Thomas's Hospital, London SE1 7EH.

Accepted 5 July 1989

\section{Methods}

THE CHAMBER

A normobaric environmental chamber was construc ted in which rats could be maintained in a hypoxic and hypercapnic environment. ${ }^{10}$ The inspired fractions of $x$ oxygen $\left(\mathrm{FIO}_{2}\right)$ and carbon dioxide $\left(\mathrm{FICO}_{2}\right)$ were measured continuously and kept at preset levels by feedback circuits. Temperature was maintained at? $23 \pm 1^{\circ} \mathrm{C}$ by thermostat control and freezer units. $A$ 12 hour light-dark cycle was used.

EXPERIMENTAL GROUPS

Groups of male CSE Wistar rats (initial weight 340-N $380 \mathrm{~g}$ ) were maintained in the chamber for 28 days in either a normoxic-normocapnic environment $\left(\mathrm{FIO}_{2} \mathrm{O}\right.$ $21 \%$, FiCO $2<1 \% ; n=12$ ), a hypoxic-normocapnicw environment $\left(\mathrm{FiO}_{2} 10 \%\right.$, Fico $\left.2<1 \% ; \mathrm{n}=10\right)$, a normoxic-hypercapnic environment $\left(\mathrm{FiO}_{2} 21 \%\right.$, Fico $5 \% ; n=8)$, or a hypoxic-hypercapnic environmentक $\left(\mathrm{FiO}_{2} 10 \%, \mathrm{FiCO}_{2} 5 \% ; \mathrm{n}=8\right)$. The exposure to chamber gases was continuous except for two periods 0 of less than 20 minutes each week when the rats were? weighed and the food and water replenished. Chamber gases were checked twice daily (Corning $168 \mathrm{pH} /$ blood $\mathbb{Q}$ gas analyser). 
TAIL ARTERY CANNULATION

At the end of the 28 days tail artery cannulation was performed under ether anaesthesia. After recovery the rats were returned to the chamber and arterial blood gas tensions were measured.

\section{MUSCLE MECHANICS}

The rats were killed with ether and their hearts removed rapidly and placed in oxygenated Kreb's solution. The right ventricle was opened and an anterior right ventricular papillary muscle was removed and mounted in an organ bath between a fixed hook and an isometric tension transducer (Statham MX2PO). The muscle was superfused with oxygenated (gas mixture $95 \%$ oxygen, $5 \%$ carbon dioxide; $\mathrm{pH} 7.4$ [0.01]) Krebs' solution (constituents in $\mathrm{mmol} / 1 ; \mathrm{NaCl} 118, \mathrm{NaHCO}_{3} 24, \mathrm{KCl} 4, \mathrm{Na}_{2} \mathrm{H}_{2} \mathrm{PO}_{4} 0.4$, $\mathrm{MgCl}_{2} 1 \cdot 0, \mathrm{CaCl}_{2} 1 \cdot 8$, glucose $5 \cdot 56$, sodium pyruvate $5.0)$ maintained at $37^{\circ} \mathrm{C}$ by a thermostat controlled water bath. The muscle was stimulated at 60 beats/ minute, pulse width $2 \mathrm{~ms}$, and amplitude 1.5 times the threshold voltage for one hour. After this maximum active tension (Tmax) the maximum rate of rise of tension (dT/dt max), the maximum rate of fall of tension ( $-\mathrm{dT} / \mathrm{dtmax})$, and the time to peak tension (TPT) were recorded and the superfusate $\mathrm{pH}$ measured.

\section{HEART WEIGHTS}

The great vessels, atria, and atrioventricular valves were dissected from the ventricles. The free wall of the right ventricle was separated by dissection at the line of reflection between the right ventricle and the interventricular septum. The left ventricular cavity was opened and blood clots removed by washing. The free wall and left ventricle were blotted dry by a standard technique and weighed. Ventricular weights were expressed as milligrams of muscle per gram of body weight.

\section{MUSCLE WEIGHTS}

At the end of the experiment muscle length was measured by a calibrated Vernier eye piece. The muscle was taken from the bath (muscle beyond the silk ties being removed), blotted dry, and weighed (Sartorius balance type 1712). Muscle cross sectional area was calculated on the assumption that the muscle was a uniform cylinder of specific gravity $1 \cdot 00$.

\section{PAPILLARY MUSCLE OXYGENATION}

We performed our experiments at physiological temperatures and a stimulation rate of 60 beats $/ \mathrm{min}$. The oxygenation of superfused papillary muscle depends on diffusion and might become inadequate as muscle cross sectional area increases, ${ }^{11}$ leading to artefactual loss of contractility. We tested the viability of the muscles of the right ventricle under these conditions by exposing the muscle to a step reduction in the oxygen tension $\left(\mathrm{PO}_{2}\right)$ of the superfusate. "Right ventricular papillary muscles from six normoxic controls (weight 400-450 g; mean (SEM) cross sectional area 0.55 $\left.(0.07) \mathrm{mm}^{2}\right)$, similar to the largest muscles used in the study (table 2), were mounted in the organ bath under the conditions described above and Tmax was recorded. By being superfused with a second, identical circuit bubbled with a gas mixture of $80 \%$ oxygen, $5 \%$ carbon dioxide, and $15 \%$ nitrogen the muscle was subjected to a step reduction in $\mathrm{Po}_{2}$ for 10 minutes and active tension recorded. The change in tension was expressed as a percentage of the tension achieved with $95 \%$ oxygen and $5 \%$ carbon dioxide.

\section{CALCULATIONS AND STATISTICAL ANALYSIS}

Rat right ventricle muscle is not uniform in shape and we have expressed mechanical properties in terms of unit muscle weight. ${ }^{12}$ Mechanical properties were compared by means of the unpaired Student's $t$ test. Tensions after changes in muscle oxygenation were compared by using paired $t$ tests. Values of $\mathrm{p}<0.05$ were taken as significant.

\section{Results}

\section{BLOOD GAS TENSIONS}

Satisfactory arterial samples were obtained from seven controls, nine hypoxic, six hypercapnic, and eight hypoxic-hypercapnic animals. In the remainder displacement of the cannula or occlusion occurred before sampling. The hypoxic group was hypocapnic and alkalotic, whereas both the hypercapnic groups had a mild respiratory acidosis (table 1). Both hypoxic groups were polycythaemic. These findings agreed with previously published results. ${ }^{13}$

\section{HEART WEIGHTS}

Selective right ventricular hypertrophy developed in both the hypoxic groups (table 2). No significant change in the weight of the left ventricle occurred in any group.

Table 1 Arterial oxygen and carbon dioxide tensions $\left(\mathrm{PaCO}_{2}, \mathrm{PaCO}_{2}\right)$ and pH (mean (SEM) values) and packed cell volume ( $P C V)$ for conscious rats breathing chamber gases

\begin{tabular}{|c|c|c|c|c|c|}
\hline & $n$ & $\begin{array}{l}\mathrm{PaO}_{2} \\
(\mathrm{kPa})\end{array}$ & $\begin{array}{l}\mathrm{PaCO}_{2} \\
(\mathrm{kPa})\end{array}$ & $p H$ & $\begin{array}{l}P C V \\
(\%)\end{array}$ \\
\hline $\begin{array}{l}\text { Controls } \\
\text { Hypoxia } \\
\text { Hypercapnia } \\
\text { Hypoxia- } \\
\text { hypercapnia }\end{array}$ & $\begin{array}{l}7 \\
9 \\
6 \\
8\end{array}$ & $\begin{array}{c}12.2(0 \cdot 5) \\
5.3(0 \cdot 1)^{*} \\
13 \cdot 3(0 \cdot 3) \\
6 \cdot 4(0 \cdot 3)^{*}\end{array}$ & $\begin{array}{l}5.1(0.1) \\
2.9(0 \cdot 1)^{*} \\
7.6(0 \cdot 1)^{*} \\
6.7(0.1)^{*}\end{array}$ & $\begin{array}{l}7.42(0.01) \\
7.48(0.03) \\
7.33(0.01)^{*} \\
7.32(0.01)^{*}\end{array}$ & $\begin{array}{l}44(1) \\
63(1)^{*} \\
41(1) \\
57(1)^{*}\end{array}$ \\
\hline
\end{tabular}

$* p<0.001$ in the comparison with controls. 
Table 2 Mechanical properties (means (SEM) values) of right ventricular papillary muscles from control rats and rats exposed to 28 days of hypoxia, hypercapnia, and hypoxia with hypercapnia

\begin{tabular}{|c|c|c|c|c|}
\hline & Controls & Hypoxia & Hypercapnia & Hypoxia-hypercapnia \\
\hline $\begin{array}{l}\text { Number } \\
\text { Tmax }(\mathrm{kN} / \mathrm{kg}) \\
+\mathrm{dT} / \mathrm{dtmax}(\mathrm{kN} / \mathrm{s} / \mathrm{kg}) \\
-\mathrm{dT} / \mathrm{dtmax}(\mathrm{kN} / \mathrm{s} / \mathrm{kg}) \\
\text { TPT (ms) } \\
\text { Cross sectional area (mm²) } \\
\text { Left ventricle weight (mg/g body weight) } \\
\text { Right ventricle (mg/g body weight) }\end{array}$ & $\begin{array}{l}12 \\
8.9(0.9) \\
49(5) \\
36(5) \\
94(3) \\
0.42(0.04) \\
1.93(0.03) \\
0.45(0.01)\end{array}$ & $\begin{array}{l}10 \\
7.8(1 \cdot 2) \\
64(8) \\
44(6) \\
101(4) \\
0.59(0.05)^{*} \\
1.89(0.05) \\
0.75(0.02)^{* *}\end{array}$ & $\begin{array}{l}8 \\
9.8(1.9) \\
62(10) \\
47(11) \\
96(4) \\
0.44(0.06) \\
2.03(0.02) \\
0.45(0.01)\end{array}$ & $\begin{array}{l}8 \\
8.9(1 \cdot 1) \\
46(9) \\
45(11) \\
101(4) \\
0.63(0.10)^{*} \\
1.93(0.02) \\
0.63(0.01)^{* *}\end{array}$ \\
\hline
\end{tabular}

$* \mathrm{p}<0.05 ; * * \mathrm{p}<0.001$

1 kilonewton $=10^{8}$ dyne.

PAPILLARY MUSCLES

The cross sectional areas of the papillary muscles of the right ventricle from the hypoxic groups were significantly greater than those from the other groups (table 2).

\section{MUSCLE OXYGENATION}

Superfusate $\mathrm{Po}_{2}$ fell from a mean (SEM) of 86.9 (3.6) to $66.9(2.5) \mathrm{kPa}$. Active tension was unchanged at $100 \%$ of the initial value $(95 \%$ confidence interval $96-$ $104 \% ; n=6)$. No change in resting tension was observed.

\section{MECHANICAL PROPERTIES}

The mechanical properties of the control group (table 2) were similar to those reported by Fry and PooleWilson. ${ }^{12}$ There was no significant difference in contractile properties between any of the acclimatised groups and the controls.

\section{Discussion}

In this paper we have shown that the isometric contractile properties of right ventricular papillary muscle from rats exposed to 28 days of hypoxia, hypercapnia, and hypoxia with hypercapnia are not depressed when studied in vitro. This result is surprising in view of previous work on experimental right ventricular hypertophy, where a fall in the contractility of the right ventricle has often been reported..$^{14-17}$

We have found that exposure to chronic hypoxia results in selective right ventricular hypertrophy, and our findings are similar to those of previous reports. ${ }^{8}$ Right ventricular hypertrophy may reduce cardiac muscle contractility as a result of inadequate capillary supply, poor energy reserves, and loss of mitochondria. ${ }^{14}$ These observations have been made on cardiac muscle that has hypertrophied as a result of pulmonary artery banding. ${ }^{714-17}$ This procedure causes very rapid and substantial changes in the morphology of the right ventricle and may lead to the death of an appreciable number of myocardial cells ${ }^{19}$ so that, not surprisingly, the muscle function of the right ventricl is often compromised. Spann ${ }^{20}$ has reviewed theo factors governing the contractile function of hypertro:phied muscle and concluded that the degree of hyper 0 trophy is of major importance. In the rat exposure tof chronic hypoxia produces only moderate hypertrophyo of the right ventricle and does not result in the gross hypertrophy seen with pulmonary artery banding. Theo degree of right ventricular hypertrophy observed ine our rats is similar to that reported in patients with chronic bronchitis and emphysema. ${ }^{21}$ We concludes that exposure to chronic hypoxia results in only a moderate degree of right ventricular hypertrophyg which is unlikely to depress cardiac function.

Exposure to chronic hypercapnia might also be expected to depress cardiac function. An acute rise ing ambient carbon dioxide tension reduces extracellular $\mathrm{pH}(\mathrm{pHe})$ and rapidly reduces intracellular $\mathrm{pH}(\mathrm{pHi})$ The rise in $\left[\mathrm{H}^{+}\right]_{\mathrm{i}}$ depresses cardiac contractility. ${ }^{12} \mathrm{~W}$ have measured contractility in vitro at a standard $\mathrm{pH}$ of 7.40. In vivo cardiac muscle from the rats exposed ton chronic hypercapnia was functioning in a more acidotic environment (pHe 7.33) and this could result in depressed contractility. We have previously shown that right ventricular muscle from rats exposed to chronic hypercapnia has an improved resistance too respiratory acidosis. ${ }^{22}$ We have used these data to? calculate the expected loss of contractility resulting from a change in pHe from 7.40 to 7.33 and found only. a small fall in Tmax of $11 \%$. The value of Tmaxs corrected for the in vivo respiratory acidosis of the hypercapnic group is $8.7 \mathrm{kN} / \mathrm{kg}$ and is not signifit cantly different from that of the control muscles $(8.9 \mathrm{kN} / \mathrm{kg})$. The contractility of right ventricular papillary muscle from rats exposed to chronic hyper capnia is unlikely to be reduced even under in vivos acid-base conditions.

There has been little work on the mechanica 5 properties of cardiac muscle exposed to chronic̄ hypoxia and hypercapnia. Kentera et $a l^{3}$ maintaine ${ }_{0}$ rats in an environment of $10 \%$ oxygen and $5 \%$ carbon $P$ dioxide for 28 days and studied the isometric propere 
ties of right ventricular muscle. Arterial blood gas tensions were not recorded and no groups exposed to pure hypoxia or hypercapnia were studied. Isometric properties were recorded under less physiological conditions than in the present study. Despite these differences they also found no significant loss of contractile function and our findings support and extend their observations.

Rat cardiac muscle adapts in the medium term to the altered work load and metabolic environment associated with exposure to chronic hypoxia and mild hypercapnia with no loss of contractile function. If these results are applicable to the human myocardium, therapeutic interventions designed to improve the contractility of the right ventricle in early chronic respiratory failure may not be successful.

\section{References}

1 Fishman AP. State of the art: chronic cor pulmonale. Am Rev Respir Dis 1976;114:775-94.

2 Alpert JS. Pulmonary hypertension and cardiac function in chronic obstructive pulmonary disease. Chest 1979;75:651-2.

3 Richens JM, Howard P. Oedema in cor pulmonale. Clin Sci 1982;62:255-9.

4 Matthay RA, Berger HJ. Cardiovascular function in cor pulmonale. Clin Chest Med 1983;4:269-95.

5 MacNee W, Wathen CG, Flenley DC, Muir AD. The effects of controlled oxygen therapy on ventricular function in patients with stable and decompensated cor pulmonale. Am Rev Respir Dis 1988;137:1289-95.

6 Whyte KF, Flenley DC. Can pulmonary vasodilators improve survival in cor pulmonale due to hypoxic chronic bronchitis and emphysema? Thorax 1988;43: 1-8.

7 Spann JF Jr, Buccino RA, Sonnenblick EH, Braunwald E. Contractile state of cardiac muscle obtained from cats with experimentally produced ventricular failure and heart failure. Circ Res 1967;21:341-54.

8 Barer GR. The physiology of the pulmonary circulation and methods of study. Pharmac Ther 1976;2:247-73.

9 Harris P, Heath D. The human pulmonary circulation. 3rd ed. Edinburgh: Churchill Livingstone, 1986:389-402.

10 Cryer A, Bartley W. The design and use of a hypoxic chamber for small animals. Laboratory Practice 1974;23:713-15.

11 Paradise NF, Schmitter JL, Surmitis JM. Criteria for adequate oxygenation of isometric kitten papillary muscle. Am J Physiol 1981;241:H348-53.

12 Fry $\mathrm{CH}$, Poole-Wilson PA. Effects of acid-base changes on excitation-contraction coupling in guinea-pig and rabbit cardiac ventricular muscle. $J$ Physiol 1981;313:141-60.

13 Pepelko WE, Dixon GA. Arterial blood gases in conscious rats exposed to hypoxia, hypercapnia or both. $J$ Appl Physiol 1975;38:581-7.

14 Alpert NR, ed. Perspectives in cardiovascular research. Vol 7. Myocardial hypertrophy and failure. New York: Raven Press, 1983.

15 Spann JF Jr, Covell JW, Eckberg DL, Sonnenblick EH, Ross J Jr, Braunwald E. Contractile performance of the hypertrophied and chronically failing cat ventricle. Am J Physiol 1972;223:1150-7.

16 Welham KC, Silove ED, Wyse RKH. Experimental right ventricular hypertrophy and failure in swine. Cardiovasc Res 1978;12:61-5.

17 Gwathmey JK, Morgan JP. Altered calcium handling in experimental pressure-overload hypertrophy in the ferret. Circ Res 1985;57:836-43.

18 Swynghedauw B, Delcayre C. Biology of cardiac overload. Pathobiol Ann 1982;12:137-83.

19 Bishop SP, Melson LR. Myocardial necrosis, fibrosis and DNA synthesis in experimental cardiac hypertrophy induced by sudden cardiac overload. Circ Res 1976;39:238-45.

20 Spann JF. Contractile and pump function of the pressureoverloaded heart. In: Alpert NR, ed. Perspectives in cardiovascular research. Vol 7. Myocardial hypertrophy and failure. 1983:19-38.

21 Scott KWM. A pathological study of the lungs and heart in fatal and non-fatal chronic airways obstruction. Thorax 1976;31:70-9.

22 Baudouin SV, Bateman NT. The effect of amiloride on the contractility of rat cardiac muscle exposed to chronic hypercapnia and acute acidosis. Cardiovasc Res 1988;22:754-8.

23 Kentera $D, Z$ dravkovic $M$. In vitro contractility of the hypertrophied right ventricle of rats with pulmonary hypertension due to confinement in "hypoxic cages." Pflügers Arch 1976;363:235-8. 